IJACT 14-1-3

\title{
International Standard for the Banking, Brokerage and Insurance Industries
}

\author{
Yong Gyu Jung ${ }^{1}$, Weon Joon Seo ${ }^{2}$, Ga-Woon Jung ${ }^{3}$, Byeong Cheol Choi ${ }^{4}$, Richard Dollein ${ }^{5}$ \\ ${ }^{1}$ Department of Medical IT Marketing, Eulji University, Korea \\ ygjung@eulji.ac.kr \\ ${ }^{2} R \& D$ Center, Softforum Co., LTD, Korea \\ seowj@softforum.com \\ ${ }^{3}$ Scientific Research Group, Neulpureun High School, Korea \\ seoul757@gmail.com \\ ${ }^{4}$ CEO, SmartGuru Co.,Ltd, Seoul, Korea \\ boksan@smartguru.co.kr \\ ${ }^{5}$ Dollomatik, Burgebrach, West Germany \\ seoul7574@gmail.com
}

\begin{abstract}
As the standards organization under ISO responsible for the development of all international financial services standards, ISO/TC 68 plays a key role in the development and adoption of new technologies in the banking, brokerage and insurance industries. In this paper many of its current work projects are introduced for developing ecommerce standards. We need to discuss the recommendations on XML conversion with ISO and other international standard organizations. Each country try to adopt the international standards even though domestic technical standards and barriers. To solve this problem of interworking between these standards, harmonization activities are nedded. For development and distribution of electronic documents to be conformed to international standards, it is enough to have the role of international activities continue to supply part of the domestic industry and the trends in participation and international standard.Our principal focus is on facilitating national and international trade, through the simplification and harmonization of processes, procedures and information flows, and so contributing to the growth of global commerce.
\end{abstract}

Keywords: Banking Service, Financial Facilitation, UN/CEFACT, ISO, KS

\section{Introduction}

ISO/TC 68 is a technical committee formed within the International Organization for Standardization (ISO), of Geneva, Switzerland, tasked with developing and maintaining international standards covering the areas of banking, securities, and other financial services. As the standards organization under ISO responsible for the development of all international financial services standards, ISO/TC 68 plays a key role in the development and adoption of new technologies in the banking, brokerage and insurance industries. Many of its current work projects involve developing ecommerce standards such as better online security for financial transactions, XML standards for financial transactions and standards to reduce the cost and delays of international financial transactions. The membership of ISO/TC 68 , consists of more than 30 organizations assigned by participating national standards bodies plus additional international standards development organizations that work collaboratively toward global financial services standards development.

Manuscript Received: Apr. 15, 2014 / Revised: May. 13, 2014 / Accepted: Jun. 10, 2014

Corresponding Author: seowj@softforum.com

Tel: +82-10-9620-9030

R\&D Center, Softforum Co., LTD, 9th FL., Hancom Tower, 463-400 Korea 


\section{Technical Subcommittee of ISO/TC68}

Within TC 68 there are, at present, three technical subcommittees, or SC's: SC2 (Security), SC4 (Securities), and SC7 (Core Banking). Subcommittees prepare and manage international standards within specific areas of concentration. Subcommittees review existing standards once every five years to update them. New standards are developed by subcommittees under the New Work Item process. New Work Items are proposed by three or more countries that are members of ISO/TC 68. If a New Work Item is approved by a super majority of countries that are members of ISO/TC 68 the New Work Item is assigned to a Working Group under a Technical Subcommittee. Each Working Group consists of technical experts in the field appointed to represent their member countries. After a sequence of revisions to committee drafts, proposed standards developed by a Working Group must be approved by a super majority of countries that are members of ISO/TC 68 before being submitted to ISO for approval as an ISO standard. TC68 Financial Services (Financial Services) to kick the Financial Industry message scheme standard (ISO 20022) and corporate identification code standard (ISO17442) is directly controlled by the TC68 Committee, in particular ISO20022 is a platform for developing financial messages in ISO TC68 the establishment of international standards for justice. Although already widely used by the domestic financial software implementation, UML design, ISO20022 defines the problem for Communication between the model not only to model the existing financial business processes and focused to create a set of reusable message through a nationwide store there. Currently the seven standards are managed as belows.

Table 1. List of standards managed by ISO/TC68

\begin{tabular}{|c|c|l|}
\hline No. & ISO No. & \multicolumn{1}{c|}{ Nane of Standard } \\
\hline 1 & ISO 17442 & Legal Entity Identifier(LEI) \\
\hline 2 & ISO 20022-1 & $\begin{array}{l}\text { UNIversal Financial Industry message scheme -Part1: Overall methodology and format specifications for } \\
\text { inputs to and outputs from the ISO 20022 Repository }\end{array}$ \\
\hline 3 & ISO 20022-2 & UNIversal Financial Industry message scheme-Part2: Roles and responsibilities of the registration bodies \\
\hline 4 & ISO 20022-3 & UNIversal Financial Industry message scheme-Part3: ISO 20022 modelling guidelines \\
\hline 5 & ISO 20022-4 & UNIversal Financial Industry message scheme-Part4: ISO 20022 XML design rules \\
\hline 6 & ISO 20022-5 & UNIversal Financial Industry message scheme-Part5: ISO 20022 reverse engineering \\
\hline 7 & ISO 20022-6 & UNIversal Financial Industry message scheme-Part6: Message Transport Characteristics \\
\hline
\end{tabular}

Enacted in ISO 20022 Part 1 - Part 6 to the following standards and amendments work together for 7, 8 and a newly developed.

Table 2. New amendments for ISO 20022 standards

\begin{tabular}{|c|c|l|}
\hline No. & ISO No. & \multicolumn{1}{c|}{ Nane of Standard } \\
\hline 1 & ISO 20022-7 & UNIversal Financial Industry message scheme-Part7: Registration \\
\hline 2 & ISO 20022-8 & UNIversal Financial Industry message scheme-Part8: ASN.1 generation \\
\hline
\end{tabular}

\subsection{SC2 : Financial Services Security}

Key management for financial services support, including authentication and manage security-related standards, currently manages a total of 17 standards are as shown below.

Table 3. List of standards managed by SC2 of ISO/TC68

\begin{tabular}{|l|l|l|}
\hline No. & ISO No. & Nane of Standard \\
\hline
\end{tabular}




\begin{tabular}{|c|c|c|}
\hline 1 & ISO $9564-1$ & $\begin{array}{l}\text { Personal Identification Number(PIN) management and security -Part1: Basic principles and requirements } \\
\text { for PINs in card-based systems }\end{array}$ \\
\hline 2 & ISO 9564-2 & $\begin{array}{l}\text { Personal Identification Number management and security - Part2: Approved algorithms for PIN } \\
\text { encipherment }\end{array}$ \\
\hline 3 & ISO/TR 9564-4 & $\begin{array}{l}\text { Personal Identification Number management and security - Part4: Guidelines for PIN handling in open } \\
\text { networks }\end{array}$ \\
\hline 4 & ISO 11568-1 & Key management(retail)-Part1: Principles \\
\hline 5 & ISO $11568-2$ & Key management(retail) -Part2: Symmetric ciphers, their key management and life cycle \\
\hline 6 & ISO $11568-4$ & Key management(retail) -Part4: Asymmetric crypto systems - Key management and life cycle \\
\hline 7 & ISO 13491-1 & Secure cryptographic devices(retail) -Part1: Concepts, requirements and evaluation methods \\
\hline 8 & ISO $13491-2$ & $\begin{array}{l}\text { Secure cryptographic devices(retail) -Part2: Security compliance checklists for devices used in financial } \\
\text { transactions }\end{array}$ \\
\hline 9 & ISO 13492 & Key management related data element-Application and usage of ISO 8583 data elements 53 and 96 \\
\hline 10 & ISO/TR 13569 & Information security guidelines \\
\hline 11 & ISO/TR 14742 & Recommendations on cryptographic algorithms and their use \\
\hline 12 & ISO 15782-1 & Certificate management for financial services -Part1: Public key certificates \\
\hline 13 & ISO 15782-2 & Certificate management for financial services -Part2: Certificate extensions \\
\hline 14 & ISO 16609 & Requirements for message authentication using symmetric techniques \\
\hline 15 & ISO/TR 19038 & Triple DEA -Modes of operation -Implementation guidelines \\
\hline 16 & ISO 19092 & Biometrics -Security framework \\
\hline 17 & ISO 21188 & Public key infrastructure for financial services -Practices and policy framework \\
\hline
\end{tabular}

New and revised standards are to be developed. It is also developed for identifying and managing the securities related standards.

Table 4. New and Revised ISO 16865 Standard

\begin{tabular}{|c|c|c|}
\hline No. & ISO No. & Nane of Standard \\
\hline 1 & ISO/AWI 16865 & Retail Financial Services Compliance Guideline: PIN Security and Key Management \\
\hline
\end{tabular}

\subsection{SC4 : Security and related financial instruments}

SC4 determines whether the LEI (Legal Entity Identifiers, global corporation demarcation code) can be used as IGI (Issuer and Guarantor Identifier) to manage the numbering system. It is used to identify the relevant standards such as securities, securities institutions for this purpose. Total of 11 standards have managed as the below.

Table 5. List of Standards managed by SC4 of ISO/TC68

\begin{tabular}{|c|l|l|}
\hline No. & ISO No. & \multicolumn{1}{c|}{ Nane of Standard } \\
\hline 1 & ISO 6166 & International securities identification numbering system (ISIN) \\
\hline 2 & ISO 8109 & Format of Eurobonds \\
\hline 3 & ISO 8532 & Format for transmission of certificate numbers \\
\hline 4 & ISO 9019 & Numbering of certificates \\
\hline 5 & ISO 9144 & Numbering of certificates \\
\hline 6 & ISO 10383 & Codes for exchanges and market identification (MIC) \\
\hline 7 & ISO 10962 & Classification of Financial Instruments (CFI code) \\
\hline
\end{tabular}




\begin{tabular}{|c|c|l|}
\hline 8 & ISO 15022-1 & $\begin{array}{l}\text { Scheme for messages (Data Field Dictionary) -Part1: Data field and message design rules and } \\
\text { guidelines }\end{array}$ \\
\hline 9 & ISO 15022-1/Cor1 & $\begin{array}{l}\text { Scheme for messages (Data Field Dictionary) -Part2: Maintenance of the Data Field Dictionary and } \\
\text { Catalogue of Messages }\end{array}$ \\
\hline 10 & ISO 15022-2 & ISO 15022-2/Cor1
\end{tabular}

SC4 of ISO 6166 has developed a new standard under revision and two counts for ISO 10962. It is also conducted an international standard of ISO18773 (Abbreviation) and ISO18774 (PSIN, financial instruments abbreviation).

Table 6. New ISO 18773 Standards

\begin{tabular}{|c|c|l|}
\hline No. & ISO No. & \multicolumn{1}{c|}{ Nane of Standard } \\
\hline 1 & ISO 18773 & Securities and related financial instruments -Abbreviations \\
\hline 2 & ISO 18774 & Securities and related financial instruments -Financial Instrument Short Name (FISN) \\
\hline
\end{tabular}

\subsection{SC7 : Core Banking}

If the TC68 SC7 to certain events occur, such as Iran bank sanctions the EU in order to manage them, numbering system to identify the bodies, specialized formats, such as managing a bank standards. Total of 13 standards have managed as belows.

Table 7. List of Standards managed by SC7 of ISO/TC68

\begin{tabular}{|c|c|c|}
\hline No. & ISO No. & Nane of Standard \\
\hline 1 & ISO 1004 & Magnetic ink character recognition -Print specifications \\
\hline 2 & ISO 4217 & \multirow{2}{*}{ Codes for the representation of currencies and funds } \\
\hline 3 & ISO 4217/Cor 1 & \\
\hline 4 & ISO 8583-1 & Interchange message specifications-Part1: Messages, data elements and code values \\
\hline 5 & ISO $8583-2$ & $\begin{array}{l}\text { Interchange message specifications -Part2: Application and registration procedures for Institution } \\
\text { Identification Codes (IIC) }\end{array}$ \\
\hline 6 & ISO $8583-3$ & $\begin{array}{l}\text { Interchange message specifications -Part3: Maintenance procedures for messages, data elements and code } \\
\text { values }\end{array}$ \\
\hline 7 & ISO 9362 & Banking telecommunication messages -Business identifier code (BIC) \\
\hline 8 & ISO 9992-1 & Messages between the integrated circuit card and the card accepting device-Part1: Concepts and structures \\
\hline 9 & ISO 11649 & Structured creditor reference to remittance information \\
\hline 10 & ISO 13616-1 & International bank account number (IBAN) -Part1: Structure of the IBAN \\
\hline 11 & ISO 13616-2 & International bank account number (IBAN) - Part2: Role and responsibilities of the Registration Authority \\
\hline 12 & ISO 18245 & Merchant category codes \\
\hline 13 & ISO 22307 & Privacy impact assessment \\
\hline
\end{tabular}

Documents of ISO 9362 are revised for task of separating into two ISO 1004 standard, and the development of mobile financial services. In particular, the current SC7 ISO 12812 mobile financial services such as mobile banking and establish standards.

Table 8. New Mobile Banking Standards

\begin{tabular}{|c|c|l|}
\hline No. & ISO No. & \multicolumn{1}{c|}{ Nane of Standard } \\
\hline 1 & ISO 1004-1 & Magnetic ink character recognition-Part 1: Print specifications for E13B \\
\hline 2 & ISO 1004-2 & Magnetic ink character recognition-Part 2: Print specifications for CMC7 \\
\hline
\end{tabular}




\begin{tabular}{|c|c|l|}
\hline 3 & ISO 9362 & Banking telecommunication messages -Business identifier code (BIC) \\
\hline 4 & ISO 12812-1 & Mobile Financial Services -Part 1: General framework \\
\hline 5 & ISO 12812-2 & Mobile Financial Services -Part 2: Security and data protection for mobile financial services \\
\hline 6 & ISO 12812-3 & Mobile Financial Services -Part 3: Financial application management \\
\hline 7 & ISO 12812-4 & Mobile Financial Services -Part 4: Mobile Person-to-Person Payments \\
\hline 8 & ISO 12812-5 & Mobile Financial Services -Part 5: Mobile Person-to-Business Payments \\
\hline 9 & ISO 12812-6 & Mobile Financial Services -Part 6: General Mobile Banking operations \\
\hline
\end{tabular}

\section{Conclusion}

In the late 1940s, members of the financial industry came together under the International Organization for Standardization (ISO) to begin developing technical standards for the banking industry to use on a world-wide basis. The original name of the organization working on banking standards was Technical Committee 68, or TC 68-Banking. Over time the scope of TC 68 expanded to include all financial services. TC 68 has continued its basic mission through industry changes and the adoption of new scientific technologies that have fostered greatly increased international commerce. One of the changes made to reflect changes to the financial industry is TC 68's name. It is now referred to as Technical Committee 68 on Banking, Securities and other Financial Services.

Recently smart phones, mobile and wireless communication environment became necessary rapidly transforming and reliability while being collateral Electronic Banking System Stability. The national committee ISO TC68, including the Bank of Korea is trying to act as a global leader in standards such as micro SD in South Korea ahead of the country at the same time to add a comment to enact these standards. Whereas the composition of the e-banking infrastructure that is generally well-organized institutional foundation is also needed. International standards are to be introduced advisory and electronic banking system is built on a policy decision to Li Ling safely. These days are trading in non-financial industries, including financial transactions of electronic banking in the small settlement service providers, as well as induce in the public interest dimension of safety and a variety of conflicting interests and social benefits of creativity and innovation in the private sectors, voluntary public infrastructure enemy will further strive to realize the nature.

\section{References}

[1] Adams, C., \& Lloyd, S. (1999). Understanding public-key infrastructure: concepts, standards, and deployment considerations. Sams Publishing.

[2] Bruggink, D., Karsten, P., \& de Meijer, C. R. (2012). The European cards environment and ISO 20022. Journal of Payments Strategy \& Systems, 6(1), 80-99.

[3] Ferris, J. M. (2012). The ISO PIA Standard for Financial Services. In Privacy Impact Assessment (pp. 307-321). Springer Netherlands.

[4] Hartsink, G. (2014). Standardisation: A conditio sine qua non for efficient payment services. Journal of Payments Strategy \& Systems, 8(1), 23-29.

[5] Hartsink, G. (2014). Standardisation: A conditio sine qua non for efficient payment services. Journal of Payments Strategy \& Systems, 8(1), 23-29.

[6] Janssens, P. (2014). The implications of legal entity identifiers on payments systems. Journal of Payments Strategy \& Systems, 8(2), 147-156.

[7] Preneel, B. (1993, January). Standardization of cryptographic techniques. In Computer Security and Industrial Cryptography (pp. 162-173). Springer Berlin Heidelberg.

[8] Sassone, V. (2014). ETAPS Award Laudatio for Kohei Honda. Bulletin of EATCS, 1(112).

[9] Stapleton, J. J. (2014). Security Without Obscurity: A Guide to Confidentiality, Authentication, and Integrity. CRC Press. 